\title{
Síntesis y caracterización de un novedoso biomaterial a base de quitosano modificado con aminoácidos
}

\author{
Synthesis and characterization of a novel \\ biomaterial based on chitosan modified \\ with amino acids
}

María Gabriela Carrero Gallardo ${ }^{1}$, Rossemberg Cardoso Barbosa ${ }^{2}$, Marcus Vinicius Lia Fook ${ }^{2}$, Marcos Antonio Sabino ${ }^{1}$

\footnotetext{
${ }^{1}$ Grupo B ${ }^{5}$ IDA - Departamento de Química de la Universidad Simón Bolívar, Caracas, Miranda,Venezuela.

${ }^{2}$ Laboratorio de Desarrollo y Evaluación de Biomateriales-CERTBIO de la Universidad Federal de Campina Grande, Campina Grande, Paraíba, Brasil.

e-mail: msabino@usb.ve
}

\section{RESUMEN}

Se realizó la modificación química de quitosano $(\mathrm{CH})$ proveniente de conchas de camarón (Litopenaeus vannamei) con aminoácidos: L-leucina (Leu) y L-tirosina (Tyr), con el fin de variar algunas de sus propiedades físicas y químicas, y ampliar su uso en la fabricación de películas y andamios, potenciando las aplicaciones del quitosano en áreas biomédicas y farmacológicas. Los derivados ( $\mathrm{CH}-\mathrm{Leu}$ y $\mathrm{CH}-\mathrm{Tyr}$ ) fueron caracterizados mediante estudios de espectroscopia infrarrojo (ATR-FTIR) para verificar la estructura de los productos modificados y las propiedades térmicas fueron analizadas mediante termogravimetría (TGA). Se realizaron ensayos de solubilidad, donde se observó que los derivados obtenidos son solubles en disoluciones acuosas a valores de pH neutro y alcalino, a diferencia del quitosano que solo es soluble bajo condiciones de $\mathrm{pH}$ ácido. La citotoxicidad de los derivados fue analizada mediante ensayos de hemocompatibilidad con eritrocitos humanos. Posteriormente se realizaron membranas a partir de los derivados de CH-Leu y CH-Tyr, y se determinó el ángulo de contacto. El proceso de biodegradabilidad en membranas se estudió a través de procesos de hidrólisis en $\mathrm{H}_{2} \mathrm{O}$ y buffer fosfato salino (PBS), $\mathrm{pH} \mathrm{7,4} \mathrm{a} 37^{\circ} \mathrm{C}$ durante intervalos de tiempo de 24, 72 y 168 h. Los andamios fueron preparados usando la técnica de electrospinning al preparar una mezcla entre poli(vinil alcohol) (PVA) y los derivados de $\mathrm{CH}$ (dada la solubilidad mostrada en agua), y la morfología de las fibras fue estudiada mediante microscopía electrónica de barrido (MEB). En general, los resultados obtenidos por FTIR, TGA y MEB sirvieron como herramientas para verificar la modificación, y estos derivados permiten ampliar las propiedades físicas y químicas del quitosano puro, principalmente en cuanto a su solubilidad, permitiendo que este novedoso biomaterial sea empleado en múltiples aplicaciones, resaltando que pueden ser mezclados con fases poliméricas sintéticas lo cual abre ventanas para el uso de este interesante biopolímero.

Palabras clave: Quitosano, L-leucina, L-tirosina, modificación química, polimezclas.

\begin{abstract}
The chemical modification of chitosan $(\mathrm{CH})$ from shrimp shells (Litopenaeus vannamei) was performed with amino acids: L-leucine (Leu) and L-tyrosine (Tyr), in order to change some of its physical and chemical properties, which allow the enhancement of the applications of chitosan in biomedical and pharmacological areas. The characterization of chitosan derivatives ( $\mathrm{CH}-\mathrm{CH}-\mathrm{Leu}$ and Tyr) was performed by infrared spectroscopy studies (ATR-FTIR) to verify the new structure of the modified compounds. The thermal stability was analyzed by thermogravimetry (TGA). Solubility tests were carried out, where it was observed that the obtained derivatives are soluble in aqueous solutions at neutral and alkaline $\mathrm{pH}$ values, unlike the chitosan that is only soluble under acid $\mathrm{pH}$ conditions. The cytotoxicity of the derivatives was analyzed by hemocompatibility tests with human erythrocytes. Subsequently, membranes were obtain from the derivatives of $\mathrm{CH}-\mathrm{Leu}$ and $\mathrm{CH}-\mathrm{Tyr}$, and contact angle was measured. The process of biodegradability in these membranes was studied through
\end{abstract}


hydrolysis processes in $\mathrm{H}_{2} \mathrm{O}$ and phosphate buffered saline (PBS), pH 7.4 at $37^{\circ} \mathrm{C}$ during time intervals of 24,72 and $168 \mathrm{~h}$. Scaffolds were prepared using the electrospinning technique to be able to prepare a mixture between poly (vinyl alcohol) (PVA) and CH derivatives (given their solubility in water) and the morphology was studied using scanning electron microscopy (SEM). In general, FTIR spectroscopy, TGA thermal analysis and SEM served as tools to verify the modification, and these derivatives allow to expand the physical and chemical properties of neat chitosan, mainly in terms of its solubility, allowing this novel biomaterial to be used in multiple applications, highlighting that they can be mixed with synthetic polymer phases which opens windows for the use of this interesting biopolymer.

Keywords: Chitosan, L-leucine, L-tyrosine, chemical modification, polyblends.

\section{INTRODUCCIÓN}

Actualmente, los polímeros naturales representan una opción viable para la obtención de nuevos biomateriales [1]. Entre los derivados poliméricos naturales se presta especial atención a un derivado de la quitina, el quitosano; el cual es un polímero semisintético de la familia de las poliaminoglucosas obtenido por desacetilación parcial de la quitina [2] [3]. Químicamente, se trata de un polímero lineal compuesto por unidades ensambladas covalentemente de D-glucosamina (unidad desacetilada) unida aleatoriamente a la N-acetil-D-glucosamina (unidad acetilada). Cuando el número de unidades desacetiladas en la quitina es $\geq 50 \%$, pasa de ser completamente insoluble a soluble en medios acuosos ácidos, siendo entonces considerado quitosano [4] [5] [6]. Sin embargo, la pobre solubilidad del quitosano cuando el $\mathrm{pH}$ es mayor a 6,5 es un grave inconveniente en muchas de sus aplicaciones potenciales. Motivo por el cual se ha incrementado el interés en modificarlo para mejorar sus propiedades y desarrollar productos seguros y eficientes [7] [8] [9] [10].

Cuando se hace referencia a la modificación de un compuesto, esto implica la modificación estructural haciendo uso de métodos químicos, físicos o biológicos para obtener numerosos derivados del producto de partida [11]. En el caso de las cadenas de quitosano, se pueden realizar modificaciones químicas gracias a la presencia de los grupos funcionales amino $\left(-\mathrm{NH}_{2}\right)$, hidroxilo $(-\mathrm{OH})$ y $\mathrm{N}$-acetilo $\left(-\mathrm{NH}-\mathrm{CO}-\mathrm{CH}_{3}\right)$, como se muestra en la figura 1. Algunas de las modificaciones que se pueden realizar en el quitosano son: fosforilación [12] [13], sulfonación [14] [15], tiolación [16] [17], cuaternización [18] [19] [20], alquilación [21] [22], acilación [21] [23], copolimerización [24] [25] [26] [27], entre otras. Todo esto con el objetivo de promover una nueva aplicabilidad al biopolímero o mejorar sus propiedades intrínsecas [5] [28] [29].

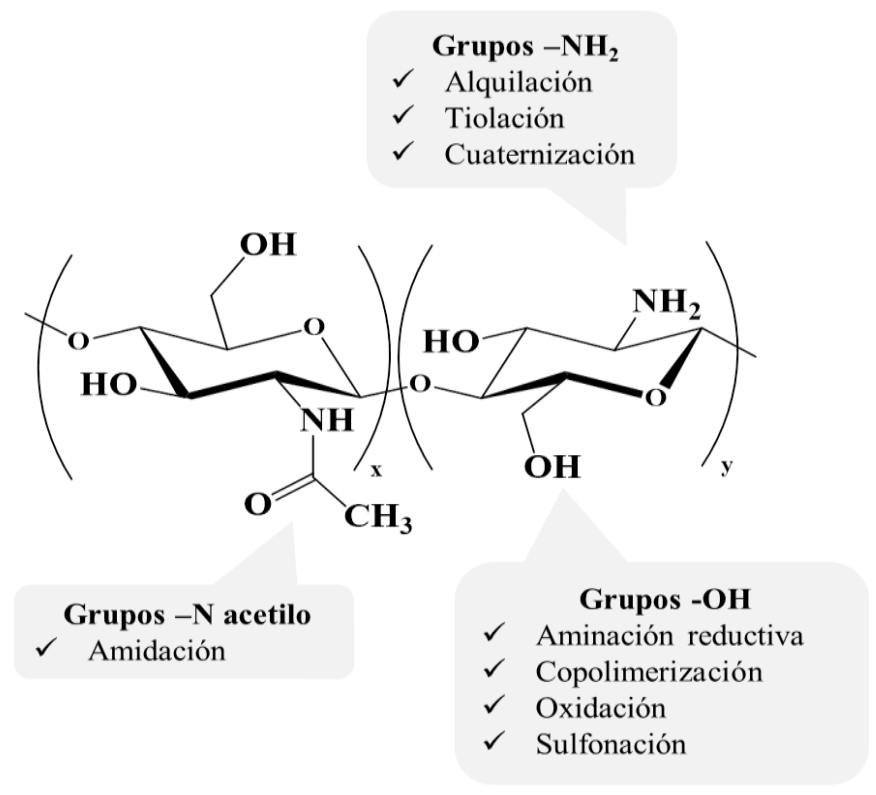

Figura 1: Reacciones químicas que permiten modificar las características y propiedades del quitosano en función de sus grupos funcionales reactivos. 
Ejemplo de estas modificaciones es la síntesis de derivados de quitosano con aminoácidos, donde se ha reportado que el acoplamiento de estos en la cadena principal del quitosano mejora sus propiedades fisicoquímicas como la solubilidad y mucoadhesividad, y da lugar a algunas características sinérgicas interesantes para su uso en la administración de fármacos y regeneración de tejidos, así como otras propiedades biomédicas potencialmente útiles tales como actividad antimicrobiana y anticoagulante [30]. Así mismo, se ha descrito en la literatura el uso de quitosano, o sus derivados, mezclado con polímeros sintéticos para obtener materiales con propiedades mejoradas a la de los polímero de partida por separado [31] [32]. Pudiendo obtener membranas o fibras para un sinfín de aplicaciones biomédicas, como: regeneración de tejidos [33], apósitos para heridas y liberación de fármacos [34], entre otras. De allí el interés en modificar químicamente el quitosano con algunos aminoácidos. En esta investigación se han seleccionado los siguientes: L-leucina y L-tirosina, dado que poseen en su grupo lateral una cadena alifática o anillo aromático, respectivamente, que pueden cambiar algunas propiedades de interés, sobre todo la solubilidad y la posibilidad de ser usado como fase dispersa en la preparación de polimezclas con polímeros sintéticos, como será evidenciado mediante la técnica de electrospinning.

\section{MATERIALES Y MÉTODOS}

\subsection{Materiales}

El quitosano $(\mathrm{CH})$ empleado tiene un grado de desacetilación mayor a $90 \%$ y un peso molecular viscosimétrico $(\mathrm{Mw})$ de $1,8 \times 10^{5} \mathrm{~g} / \mathrm{mol}$. Fue extraído de conchas de camarón de la especie Litopenaeus vannamei y suministrado por el Laboratorio de Desarrollo y Evaluación de Biomateriales-CERTBIO. Para la modificación se usó N,Ndiciclohexilcarbodiimida (DCC), ácido acético, L-Leucina (Leu) y L-Tirosina (Tyr) de Sigma Aldrich. Para la preparación de la polimezcla se usó poli(vinil alcohol) (PVA) (Mw 1,4x10 $\mathrm{g} / \mathrm{mol}$ ) de Himedia. Etanol de Riedel-de Haën. Tritón X-100 de Scharlau Chemie. Todos los reactivos empleados son de grado analítico.

\subsection{Síntesis de los derivados de quitosano con aminoácidos}

La reacción de conjugación de los aminoácidos con quitosano para la preparación de los derivados se llevó a cabo mediante un acoplamiento directo en presencia de DCC, entre los grupos amino libres del quitosano y el ácido carboxílico de los aminoácidos, como se muestra en la figura 2 [35] [36] [37]. Inicialmente se preparó una solución etanólica de DCC/Tyr o DCC/Leu (proporción 1:1). Dicha solución se mantuvo en agitación constante por 20 min a $60^{\circ} \mathrm{C}$ para activar los grupos carbonilo presentes en el aminoácido. Una vez activado el aminoácido, se adicionó gota a gota sobre una solución de quitosano al $1 \%(\mathrm{p} / \mathrm{v})$ en ácido acético al 1\% (v/v). La solución final se mantuvo en agitación constante por $24 \mathrm{~h}$ a temperatura ambiente. 

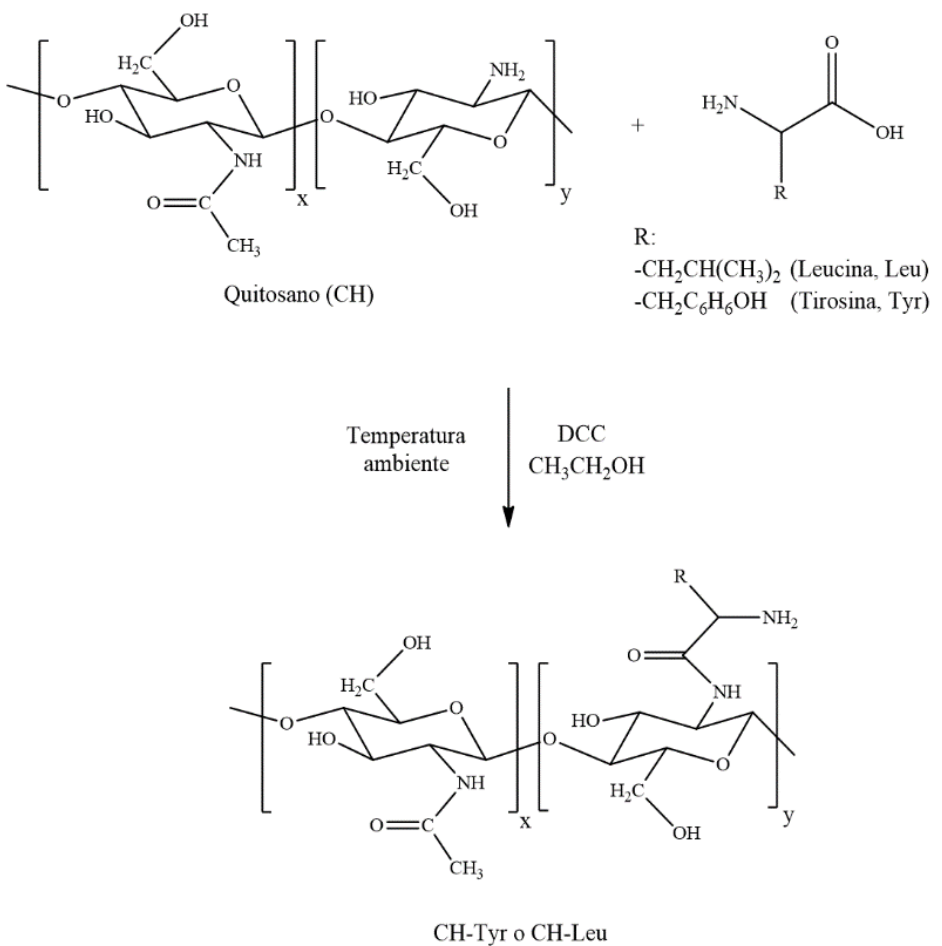

Figura 2: Reacción de quitosano con aminoácidos (Tyr o Leu) en presencia de DCC

Terminada la reacción, todo el producto fue vertido en membranas de latex para dializarse por $48 \mathrm{~h}$ en agua desionizada a temperatura ambiente. El agua de la diálisis fue sustituida cada $12 \mathrm{~h}$. Culminada la diálisis se adicionó acetona fría al contenido de las membranas para precipitar el gel de quitosano. Se decantó el sobrenadante y el gel se lavó por triplicado con etanol y agua. Una vez purificado cada derivado, $\mathrm{CH}-\mathrm{Tyr}$ o CHLeu, se congeló y fue liofilizado para su posterior caracterización.

\subsection{Caracterización de CH-Tyr y CH-Leu}

\subsubsection{Espectroscopia ATR-FTIR}

La espectroscopía Infrarrojo por Transformada de Fourier (FTIR) se realizó en un equipo Perkin Elmer (modelo spectrum 400) acoplado a un cristal de Reflectancia Total Atenuada (ATR) de ZnSe, realizando 32 barridos a 4 $\mathrm{cm}^{-1}$ resolución, entre 4000-600 $\mathrm{cm}^{-1}$. Los espectros se graficaron usando el programa OriginPro.

\subsubsection{Test de solubilidad}

Como ya se mencionó, el quitosano presenta una solubilidad limitada a medios acuosos ácidos, restringiendo la posibilidad de trabajar con este en soluciones a $\mathrm{pH}$ neutro, básico, o bien en solventes orgánicos. Es por ello que una vez realizada la modificación se procedió a la evaluación de la solubilidad de CH-Tyr y CH-Leu en soluciones acuosas a pH ácido (pH 3,0), neutro $(\mathrm{pH} 7,0)$ y básico $(\mathrm{pH} \mathrm{10,0).}$

\subsubsection{Análisis térmico}

El comportamiento térmico del quitosano puro y de los conjugados $\mathrm{CH}$-Tyr y $\mathrm{CH}$-Leu fue estudiado en un Mettler Toledo (modelo TGA/SDTA851) en un rango de temperatura de $25-600^{\circ} \mathrm{C}$ a una velocidad de calentamiento de $20^{\circ} \mathrm{C} / \mathrm{min}$, lo cual permitió monitorear los cambios físicos y químicos en este tipo de biopolímero. La atmósfera se mantuvo con un flujo de $\mathrm{N}_{2}(\mathrm{~g})$ a $40 \mathrm{~mL} / \mathrm{min}$. 


\subsection{Preparación de membranas}

Una vez verificada la solubilidad de los derivados en soluciones acuosas, la preparación de las membranas fue realizada por el método de evaporación de solvente.

Membrana de quitosano: Para ello se preparó una solución de quitosano al 1\% (p/v) en ácido acético al 1\%. Se mantuvo en agitación magnética hasta disolver todo el sólido (aprox. $30 \mathrm{~min}$ ). Luego se dispuso la solución en cápsulas de Petri hasta cubrir el fondo de la misma y se dejó secando a temperatura ambiente durante 5 días. Una vez seca la película, se despegaron de las cápsulas y se neutralizaron sumergiéndolas en una solución de $\mathrm{NaOH} 1 \mathrm{M}$ por $30 \mathrm{~s}$. Finalmente se lavaron sumergiéndolas en agua nanopura durante $2 \min$ [38].

Membranas de los derivados: Se prepararon a partir de una solución a 1\% (p/v) en $\mathrm{H}_{2} \mathrm{O}$ destilada (pH 6,1). Igualmente se agito hasta disolver por completo el sólido (aprox. 5 min), seguido se agregó la solución en cápsulas de Petri y se dejaron secar a temperatura ambiente durante 5 días.

\section{5. Ángulo de contacto}

Una vez verificado el proceso de preparación de las membranas, se procedió a medir el ángulo de contacto, con el fin de estudiar como varía el carácter hidrofóbico del quitosano una vez realizada la modificación con L-tirosina y L-leucina. También se verificó la formación de membranas a partir de las polimezclas a base de PVA con CH y sus derivados.

El ensayo consistió en preparar películas de dichas soluciones acuosas sobre laminas porta objetos de vidrio. Las soluciones poliméricas de $\mathrm{CH}, \mathrm{CH}-\mathrm{Tyr}, \mathrm{CH}-\mathrm{Leu}$ estaban al $1 \% \mathrm{p} / \mathrm{v}$ y las mezclas con PVA, se describen en la tabla 1. Para garantizar un buen mezclado, se dejaron bajo agitación magnética por $2 \mathrm{~h}$ a temperatura ambiente.

Formadas las películas, se dispuso una gota de $\mathrm{H}_{2} \mathrm{O}(20 \mu \mathrm{L})$, y se hizo el respectivo registro fotográfico, para posteriormente medir el ángulo sobre la superficie del material. El estudio se realizó por triplicado y el ángulo formado por el solvente sobre la membrana fue analizado empleando el programa Digimizer.

Tabla 1: Concentración de soluciones empleadas para obtener películas a partir de la mezcla de PVA:CH, PVA:CH-Tyr y PVA:CH-Leu

\begin{tabular}{ccc}
\cline { 2 - 3 } & Concentración $(\mathrm{p} / \mathrm{v})$ & Solvente \\
\hline \hline PVA/CH $(100 / 0)$ & $8 \%$ & $\mathrm{H}_{2} \mathrm{O}$ \\
\hline PVA/CH $(0 / 100)$ & $2 \%$ & Ácido acético al 1\% \\
\hline PVA/CH-Tyr (80/20) & $2 \%$ & $\mathrm{H}_{2} \mathrm{O}$ \\
\hline PVA/CH-Leu (80/20) & $2 \%$ & $\mathrm{H}_{2} \mathrm{O}$ \\
\hline
\end{tabular}

\subsection{Degradación}

El porcentaje de degradación de las membranas de $\mathrm{CH}$, CH-Tyr y CH-Leu se estudió incubando las muestras en $\mathrm{H}_{2} \mathrm{O}$ y buffer fosfato salino (PBS, $\mathrm{pH} 7,4$ ) a $37^{\circ} \mathrm{C}$ durante intervalos de tiempo de 24,72 y $168 \mathrm{~h}$. Culminada la incubación, las muestras fueron lavadas cuidadosamente con agua nanopura para retirar los iones que pudieron ser absorbidos en la superficie de la membrana y luego se secaron (estufa a $40^{\circ} \mathrm{C}$ ) y pesaron. El procedimiento fue diseñado variando algunas condiciones del trabajo realizado por SOWJANYA et al. [39] y TRONCI et al.[40]. Este procedimiento fue realizado por triplicado y el porcentaje de degradación de calculó siguiendo la ecuación 1 a continuación:

$$
\text { Degradación (\%) }=\frac{M_{\mathrm{o}}-\mathrm{M}_{\mathrm{d}}}{\mathrm{M}_{\mathrm{o}}} \times 100
$$

donde: $\mathrm{M}_{\mathrm{o}}$ es la masa inicial de la membrana y $\mathrm{M}_{\mathrm{d}}$ es la masa de la membrada degradada. 


\subsection{Preparación de fibras mediante electrospinning}

Partiendo de las soluciones descritas en la tabla 1, se procedió a la preparación de membranas porosas a partir de las polimezclas de PVA:CH, PVA:CH-Tyr y PVA:CH-Leu, en proporción 80:20, empleando la técnica de electrohilado o electrospinning. Se empleó un equipo electrospinning de configuración vertical, con un voltaje de $30 \mathrm{kV}$ y la distancia punta-colector de $12,5 \mathrm{~cm}$, a temperatura y humedad relativa ambiental.

\subsection{Estudio morfológico de fibras}

La morfología de las membranas obtenidas por electrospinning se estudió usando un Microscopio Electrónico de Barrido marca JEOL modelo JSM-6390. Previo al análisis, se recubrieron las muestras con una capa fina de oro en un equipo de metalización marca Balzars-SCD 030. El diámetro de las fibras fue analizado empleando el programa Digimizer.

\subsection{Estudio de hemocompatibilidad}

La evaluación de hemocompatibilidad se realizó estudiando la interacción entre el CH y sus derivados N-acilados con eritrocitos humanos. Primero se recogió sangre humana en tubos recubiertos con una solución de sal disódica de ácido etilendiaminotetraacético $0,5 \mathrm{M}$ (EDTA- $\left.\mathrm{Na}_{2}\right)$ como anticoagulante. Los eritrocitos se obtuvieron centrifugando la sangre a $1500 \mathrm{rpm}$ durante $10 \mathrm{~min}$ y el sedimento se lavó tres veces usando una solución isotónica de $\mathrm{NaCl}$ al 0,9\%. Posteriormente los eritrocitos se suspendieron en PBS (pH 7,4) a una concentración final de $2,5 \%$.

La actividad hemolítica del quitosano puro y los derivados $\mathrm{CH}$-Tyr y CH-Leu se evaluó a concentraciones crecientes $(25,50,100,200$ y $500 \mu \mathrm{g} / \mathrm{mL})$. Este ensayo también se realizó sobre las membranas obtenidas mediante electrospinning, usando recuadros de $1 \mathrm{~cm}^{2}$. Finalmente, se adicionó los eritrocitos suspendidos en PBS $(800 \mu \mathrm{L})$ a la muestra problema $(200 \mu \mathrm{L})$, para luego ser incubadas en una estufa a $37^{\circ} \mathrm{C}$ durante $1 \mathrm{~h}$.

Para este estudio se consideró el tratamiento con PBS como control negativo ( $0 \%$ hemólisis) y el tratamiento con solución de Tritón X-100 al 1\% (v/v) como control positivo (100\% hemólisis). Transcurridos la incubación, las muestras se centrifugaron a $1500 \mathrm{rpm}$ durante $10 \mathrm{~min}$ y se midió la absorbancia del sobrenadante a $540 \mathrm{~nm}$ usando un espectrofotómetro UV marca HP AGILENT modelo 8452 con arreglo de diodo. El porcentaje de hemólisis se calculó usando la ecuación 2.

$$
\text { Hemólisis }(\%)=\frac{A_{\text {polímero }}-A_{P B S}}{A_{\text {Tritónx }}-A_{P B S}} \times 100
$$

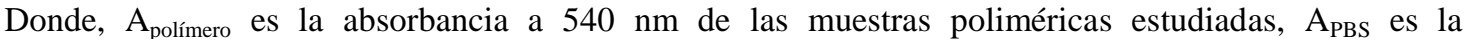
absorbancia a $540 \mathrm{~nm}$ de la muestra tratada con PBS $\left(\mathrm{pH} \mathrm{7,4)} \mathrm{y} \mathrm{A}_{\text {TritónX }}\right.$ es la absorbancia a $540 \mathrm{~nm}$ de la muestra tratada con tritón X-100 al 1\%. Todas las muestras fueron analizadas por triplicado.

El análisis por microscopia óptica de los eritrocitos luego de la incubación se realizó para observar los posibles cambios morfológicos, usando un microscopio marca Leica (modelo DM2500) y aumento de 100 X. Las imágenes fueron capturadas con una cámara Celestron de 2 MP acoplada al microscopio. El diseño experimental fue basado en los trabajos publicados por EVANS et al. [41], SARWAR et al. [42], SHARMA y SINGH [43] y TAMER et al. [38].

\section{RESULTADOS Y DISCUSIÓN}

\subsection{Caracterización de los derivados de quitosano $\mathrm{CH}$-Tyr y $\mathrm{CH}$-Leu}

\subsubsection{Espectroscopia FTIR}

La caracterización consistió en un estudio por FTIR, para evidenciar la aparición o desaparición de bandas producto de la formación o ruptura de enlaces, respectivamente. La figura 3 muestra el espectro FTIR del CH, CH-Tyr y CH-Leu en la región de $4000-600 \mathrm{~cm}^{-1}$ (fig. 3A) y la región de huella dactilar entre $1800-800 \mathrm{~cm}^{-1}$ (fig. 3B). En el espectro del quitosano es posible observar sus bandas características [44] [45]: (a) banda ancha entre los 3300-3500 cm $\mathrm{cm}^{-1}$, correspondiente al enlace -OH y -NH; (b) banda en $3000 \mathrm{~cm}^{-1}$ estiramiento -CH; (c) señal en $1653 \mathrm{~cm}^{-1}$ estiramiento del grupo carbonilo $(\mathrm{C}=\mathrm{O})$ de la unidad acetilada del polisacárido; y $(\mathrm{d})$ banda cercana a $1000 \mathrm{~cm}^{-1}$ atribuida al estiramiento $\mathrm{C}-\mathrm{O}-\mathrm{C}$ del esqueleto polimérico. 
En cuanto al espectro de los productos de la modificación, es posible apreciar de forma más definida las señales entre los $1700-1500 \mathrm{~cm}^{-1}$ (ver figura 3B). En esta región se identifican las bandas correspondientes a la vibración del grupo carbonilo próxima a $1600 \mathrm{~cm}^{-1}$ (señal amida I) y la banda correspondiente a la combinación de tensión entre el $\mathrm{C}=\mathrm{O}$ y la flexión del enlace $\mathrm{N}-\mathrm{H}$ por encima de $\operatorname{los} 1500 \mathrm{~cm}^{-1}$ (señal amida II), las cuales no se presentan para el quitosano puro. Adicionalmente, en el espectro del CH-Tyr se observa una banda en $1260 \mathrm{~cm}^{-1}$ y $797 \mathrm{~cm}^{-1}$ correspondientes al enlace $-\mathrm{OH}$ del grupo fenol y los enlaces vinílicos del anillo aromático, respectivamente. Por su parte, en el espectro del CH-Leu se presentan las bandas en $1311 \mathrm{~cm}^{-1}$ del grupo isopropil y en $800 \mathrm{~cm}^{-1}$ debido al metileno vecino a grupo isopropil [45] [46] [47].
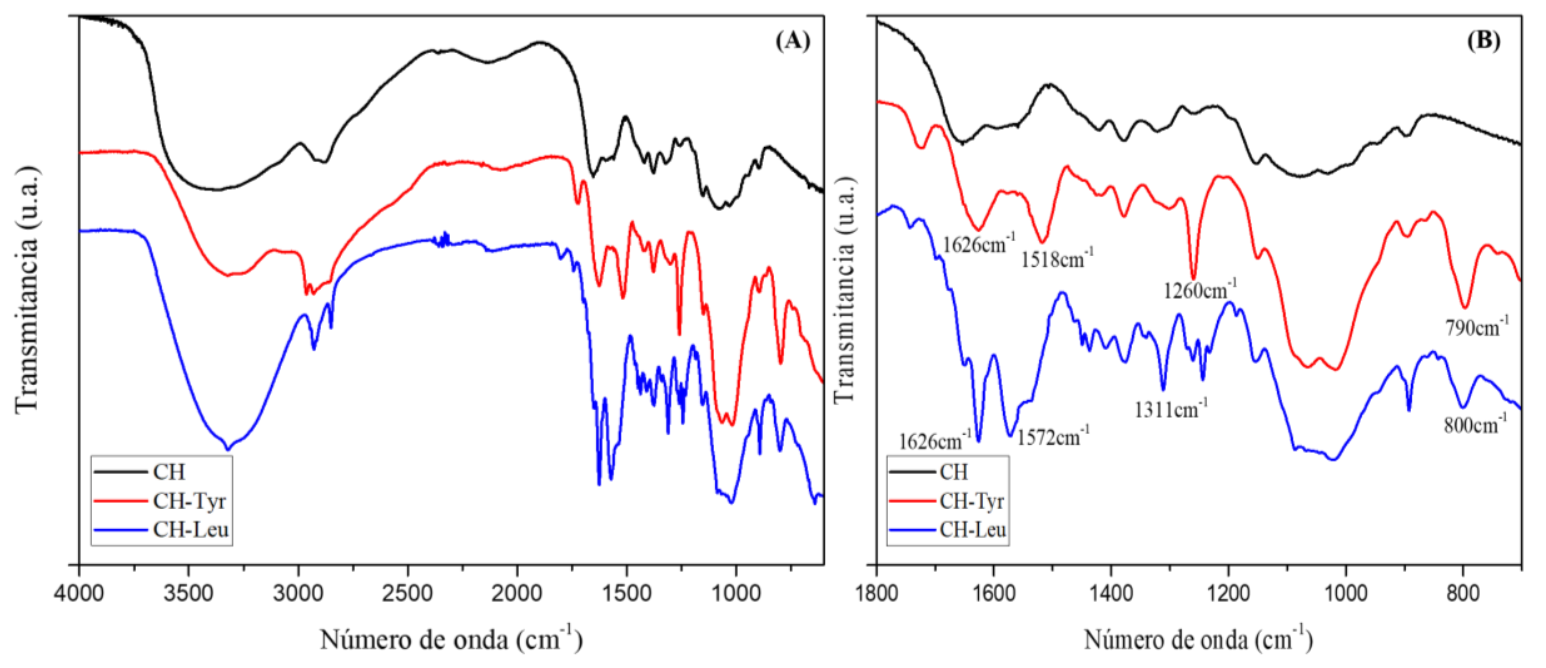

Figura 3: Espectro FTIR del CH, CH-Tyr y CH-Leu en la región de 4000-600 $\mathrm{cm}^{-1}$ (A) y la región de huella dactilar entre $1800-800 \mathrm{~cm}^{-1}(\mathrm{~B})$.

\subsubsection{Solubilidad}

Estudios previos indican la modificación de quitosano con aminoácidos como L-lisina y L-arginina, para lograr obtener derivados con solubilidad mejorara en disoluciones acuosas que permitan ampliar el rango de aplicaciones biomédicas en base a este polisacárido [45] [30]. Partiendo de estos reportes, se evaluó la solubilidad de $\mathrm{CH}$-Tyr y $\mathrm{CH}$-Leu en medios acuosos a diferentes $\mathrm{pH}$, encontrando que ambos derivados son solubles en

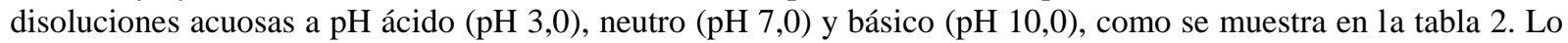
cual representa una ventaja en comparación al quitosano puro. Pues permite evitar el uso de solventes ácidos durante su tratamiento para investigaciones futuras y desarrollo de nuevos biomateriales.

Tabla 2: Solubilidad del CH, CH-Tyr y CH-Leu en $\mathrm{H}_{2} \mathrm{O}$ destilada y soluciones acuosas a diferentes valores de $\mathrm{pH}$.

\begin{tabular}{|c|c|c|c|c|}
\hline \multirow{2}{*}{ Compuesto } & \multirow{2}{*}{$\begin{array}{c}\mathrm{H}_{2} \mathrm{O} \\
\text { destilada }\end{array}$} & \multicolumn{3}{|c|}{ Solución a pH } \\
\cline { 3 - 5 } & $\mathrm{I}$ & $\mathrm{S}$ & Neutro $(7,0)$ & Básico $(10,0)$ \\
\hline \hline $\mathrm{CH}$ & $\mathrm{S}$ & $\mathrm{S}$ & $\mathrm{I}$ & $\mathrm{I}$ \\
\hline CH-Tyr & $\mathrm{S}$ & $\mathrm{S}$ & $\mathrm{S}$ & $\mathrm{S}$ \\
\hline CH-Leu & $\mathrm{S}$ & $\mathrm{S}$ & $\mathrm{S}$ \\
\hline
\end{tabular}

I: insoluble; S: soluble

\subsubsection{Análisis termogravimétrico}

En la figura 4 podemos observar el termograma TGA obtenido para las muestras liofilizadas de $\mathrm{CH}, \mathrm{CH}-\mathrm{Tyr}$ y $\mathrm{CH}$-Leu. En la curva del $\mathrm{CH}$ se aprecian dos fases, la primera entre los $50-150^{\circ} \mathrm{C}$ correspondiente a la perdida de agua (deshidratación, lo cual corresponde a una pérdida de alrededor de un $10 \%$ de agua), a partir de esa temperatura se aprecia una cierta estabilidad térmica, que luego se interrumpe, alrededor de los $280^{\circ} \mathrm{C}$ con una caída abrupta hasta el intervalo entre $\operatorname{los} 360-400^{\circ} \mathrm{C}$ lo cual representa un proceso de descomposición termo- 
oxidativa que se corresponde a procesos de oxidación, desacetilación, y por lo tanto a la degradación y descomposición de la cadena del polisacárido, como ha sido reportado en trabajos anteriores [37].

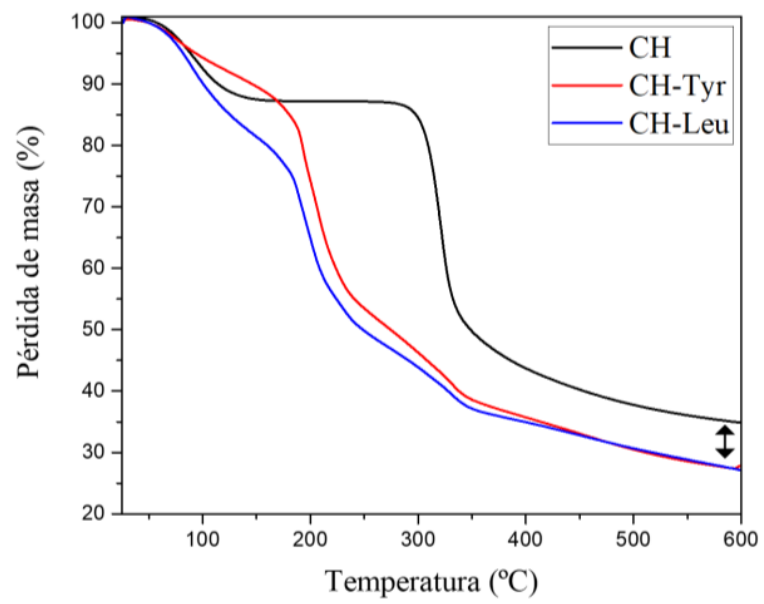

Figura 4: Termograma TGA del CH, CH-Tyr y CH-Leu

En cuanto a los derivados, se aprecia un comportamiento diferente, lo cual ya es un indicativo de que efectivamente el proceso de modificación se llevó a cabo, ratificando así lo expuesto en los análisis espectroscópicos FTIR. En este caso, se observa una primera fase producto del proceso de deshidratación correspondiente a la pérdida de entre $15-25 \%$ de agua retenida por la muestra, debido a los grupos funcionales (-CO- , -NH-) de los aminoácidos presentes en los derivados lo cual modifica su hidrofobicidad [42]. Este cambio de hidrofobicidad será ratificado más adelante cuando se presente los resultados de ángulo de contacto. A partir de allí, y por encima de los $180^{\circ} \mathrm{C}$ de igual forma se observa la segunda fase de la termo-descomposición, que corresponde no solo a la desacetilación y oxidación, sino también al desprendimiento de los grupos injertados a la cadena del polisacárido [45]; lo cual se agudiza por encima de los $350^{\circ} \mathrm{C}$. Se puede inferir que la diferencia observada entre la curva del $\mathrm{CH}$ y las curvas de los derivados, corresponde al grado de inserción ocurrida producto de la modificación, y lo cual está señalado ( $)$ entre los $550-600^{\circ} \mathrm{C}$.

\section{2. Ángulo de contacto}

La hidrofilicidad es un parámetro fundamental para determinar el carácter hemocompatible de biomateriales poliméricos, pues rige el proceso de adsorción de proteínas sobre la superficie del material después de la exposición a la sangre [48] [49]. Estudios indican que durante los primeros minutos de contacto entre el material y la sangre, la absorción de proteínas es muy similar entre materiales hidrofílicos e hidrofóbicos, pero luego, la propiedad de adsorción en superficies hidrofílicas es menor [50] y en consecuencia la formación de trombos es baja [49]. En general, se ha demostrado que el aumento de la hidrofilicidad superficial de un material mejora la biocompatibilidad de los dispositivos médicos, al menos de forma in vitro [51]. De allí el interés en evaluar el carácter hidrofílico de los derivados de quitosano una vez realizada la modificación con aminoácido o la mezcla con PVA.

Tabla 3: Ángulo de contacto del CH, CH-Tyr, CH-Leu y de las polimezclas PVA/biopolímero.

\begin{tabular}{cc}
\hline Muestra & $\begin{array}{c}\text { Ángulo de contacto }\left(^{\circ}\right) \\
\text { con } \mathrm{H}_{2} \mathrm{O}\end{array}$ \\
\hline \hline CH & $70,9 \pm 0,7$ \\
\hline CH-Tyr & $48,3 \pm 1,3$ \\
\hline CH-Leu & $46,2 \pm 1,9$ \\
\hline PVA:CH & $62,2 \pm 0,6$ \\
\hline PVA:CH-Tyr & $45,0 \pm 2,3$ \\
\hline PVA:CH-Leu & $40,3 \pm 1,3$ \\
\hline PVA & $29,7 \pm 1,3$ \\
\hline
\end{tabular}


A pesar de que el quitosano posee en su unidad estructural grupos funcionales que pueden presentar afinidad con el agua, la estructura general del mismo, conformado fundamentalmente con anillos tipo azúcar y dado su alto peso molecular, le confieren a este material un carácter más hidrofóbico que hidrofílico. Sin embargo, como se muestra en la tabla 3, el carácter hidrofóbico del quitosano disminuyó una vez realizada la modificación con Tyr o Leu, mostrando un ángulo de contacto inferior al del quitosano, y el mismo comportamiento se muestra en las polimezclas. En el caso de las polimezclas el valor del ángulo de contacto se encuentra por encima del PVA (altamente hidrofílico) pero por debajo del quitosano (hidrofóbico). Como se aprecia, el $\mathrm{CH}$ tiene un componente hidrofóbico considerable al presentar un ángulo de $\sim 71^{\circ}$, pero al injertar los aminoácidos a su estructura, este valor desciende a $46-48^{\circ}$, debido a que dichos aminoácidos aportan grupos funcionales afines al agua como se mencionó anteriormente (sección 3.1.3). Asimismo, al realizar las polimezclas, la presencia física de las cadenas de PVA permite aumentar el nivel de hidrofilicidad debido al contenido de grupos hidroxilo en el polímero sintético, observando un ángulo de contacto entre $40-45^{\circ}$. En relación a los valores reportados en la tabla 3, estos corresponden a un promedio entre medidas realizadas a cada lado del punto de contacto de cada gota dispuesta sobre la superficie de la muestra. Este procedimiento se realizó por triplicado en cada película (ver sección 2.5), lo cual permite garantizar la validez de los valores obtenidos.

Estos resultados permiten inferir que las modificaciones realizadas disminuyen el carácter hidrofóbico del quitosano, lo cual podría aumentar la capacidad de hinchamiento de las membranas, así como mejorar: la permeabilidad para el vapor de agua y gases, el transporte de fluidos a través de la membrana y la selectividad para el transporte de sustancias voluminosas y apolares [52]. Por lo tanto, se abre un abanico de posibilidades para las aplicaciones que podrían tener las membranas preparadas a partir de los derivados sintetizados. Adicionalmente, se ha descrito en la literatura que películas con características similares, promueven la absorción de lisozimas [53] y, en consecuencia, podría alterar su proceso de degradación favoreciendo la aplicación que pueda tener el material.

\subsection{Degradación}

El quitosano es susceptible a factores ambientales como la humedad y temperatura, de igual manera a condiciones de procesamiento como calentamiento o congelación, lo que puede causar estrés en su estructura y conllevar a la degradación del polímero [9]. Pero, según la aplicación específica que vaya a tener el material, la velocidad de degradación juega un papel protagónico, ya que, la cinética de degradación puede afectar los procesos celulares, incluyendo el crecimiento celular, la regeneración de tejido y la respuesta del huésped [54] [55] [56] o condicionar un sistema para la liberación de fármacos [9].

En la figura 5 se aprecia cómo una vez realizada la modificación se ve alterada la degradación hidrolítica del quitosano a $37^{\circ} \mathrm{C}$, tanto en $\mathrm{H}_{2} \mathrm{O}$ como en PBS. Durante las primeras $72 \mathrm{~h}$ de estudio, el quitosano no presenta ninguna evidencia de degradación, mientras que los derivados superan el $10 \%$ de degradación. Transcurridas $168 \mathrm{~h}$, se ve como la degradación de los derivados supera el $20 \%$ de pérdida de masa, mientras que el quitosano puro no alcanza el 10\%. A pesar de que los derivados mostraron una alta solubilidad en solución acuosa, se ve que una vez formadas las membranas, y dado el ordenamiento molecular que puede ocurrir durante el proceso de formación de las mismas por secado lento, se favorecen las interacciones intra e intermoleculares entre las cadenas del biopolímero, lo cual hace posible que aún se mantenga cierta estabilidad dimensional, dado que luego de una semana $(168 \mathrm{~h})$ de la exposición al medio hidrolítico, aún se mantiene alrededor del 60-70\% de la masa de dichas membranas. Este resultado, nos permite inferir que estos derivados pueden ser empleados para el diseño de andamios para ingeniería de tejidos o para sistemas de liberación de fármacos [57]. 

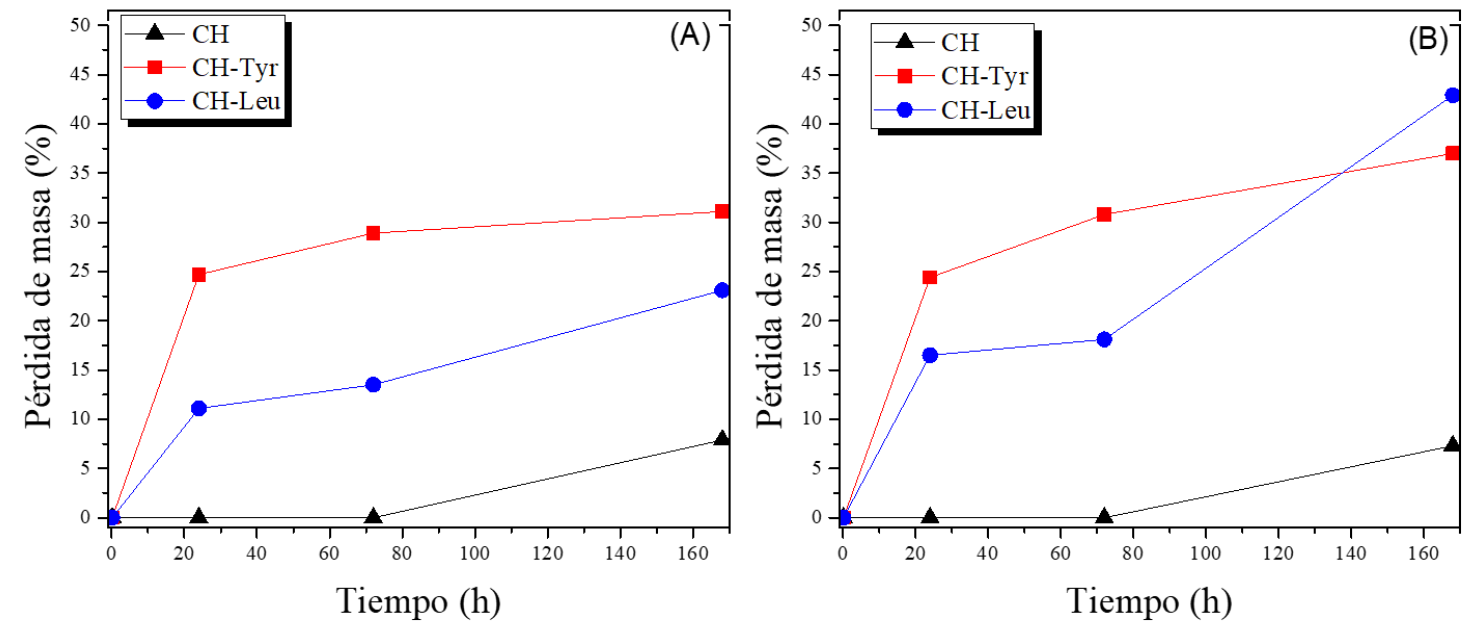

Figura 5: Evidencia del proceso de degradación por hidrólisis de las membranas de $\mathrm{CH}$, $\mathrm{CH}$-Tyr y $\mathrm{CH}$-Leu en $\mathrm{H}_{2} \mathrm{O}$ destilada $(\mathrm{pH} 6,1)(\mathrm{A})$ y $\mathrm{PBS}(\mathrm{pH} 7,4)(\mathrm{B})$ a $37^{\circ} \mathrm{C}$ en función del tiempo de exposición al medio hidrolítico.

\subsection{Morfología de las membranas obtenidas mediante electrospinning.}

En esta investigación, no solo es de relevancia verificar los cambios en las propiedades física y química de los derivados de quitosano sintetizados, sino también ver la potencialidad de aplicación que tienen para diferentes campos. Dentro de la ingeniería de tejidos, los andamios representan estructuras porosas tridimensionales (3D) fabricadas a partir de polímeros biodegradables, que dan cabida a las células y sirven de soporte mecánico a un tejido que está en proceso de recuperación o regeneración [58]. Una de las técnicas empleadas para la obtención de estructuras tipo andamio es el electrospinning [59], sin embargo, en el caso del quitosano, las fuerzas repulsivas entre los grupos iónicos dentro del esqueleto polimérico, que surgen debido a la aplicación de un campo eléctrico elevado durante el electrospinning y su solubilidad en condiciones ácidas, restringen la formación de fibras continuas, favoreciendo la formación de gotas o perlas, como se muestra en la figura 6. Es por ello que en la literatura científica pocos reportes se han encontrado respecto a la formación de fibras continuas de quitosano puro en soluciones acuosas. En cuando a los parámetros evaluados para la formación de fibras de quitosano puro, se consideró la distancia punta-colector en un rango de 5 a $15 \mathrm{~cm}$ y el voltaje aplicado se varió desde los 5 hasta los $30 \mathrm{kV}$.
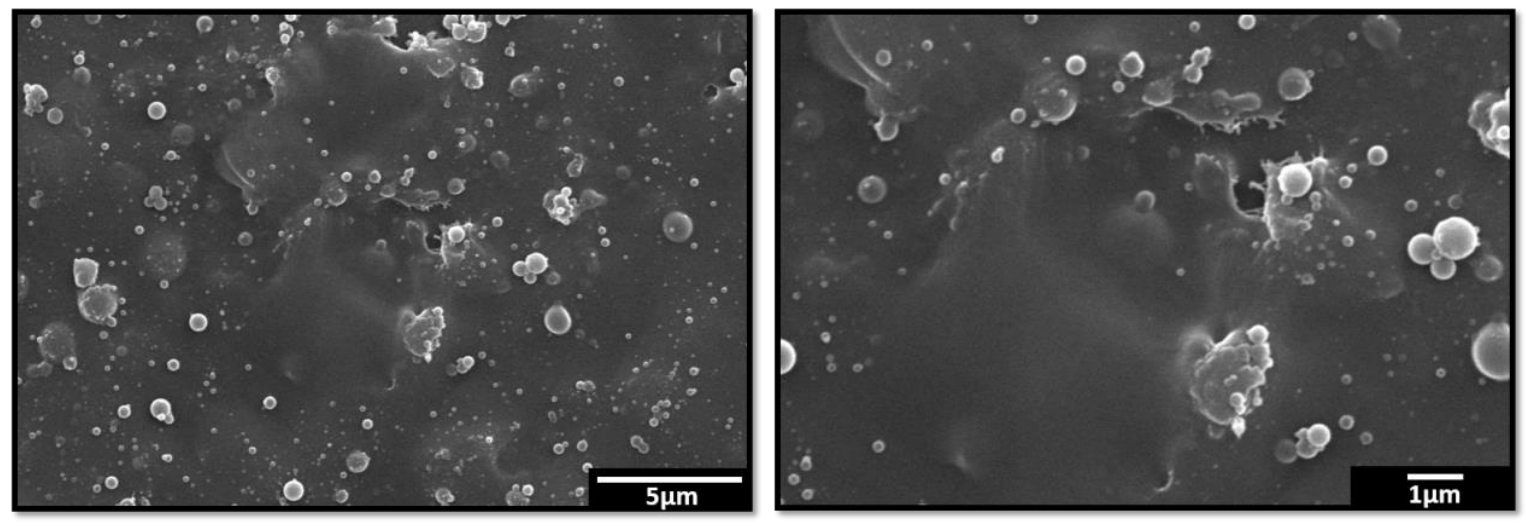

Figura 6: Microfotografía MEB (izquierda 5000X, derecha 1000X) de una solución de CH 1\% (en ácido acético) donde sólo se aprecia la formación de gotas o perlas, sin evidencia de la formación de fibras (Voltaje $10 \mathrm{kV}$, distancia punta-colector de $10 \mathrm{~cm})$.

Para lograr una cierta viscosidad que permita el proceso de formación de un cono de Taylor estable y luego la formación de fibras continuas, fue necesario mezclar el quitosano con una fase polimérica sintética que, 
en este caso, se trató de PVA. Por otro lado, si la compatibilidad entre la fase CH y PVA es baja, el proceso de formación de fibras continuas también se presenta con dificultad. Es por ello que para el caso de los derivados CH-Leu y CH-Tyr, al ser más solubles en fase acuosa, se mejora la tensión interfacial entre ellos y la fase PVA permitiendo que la polimezcla pueda presentar mejor compatibilidad entre fases, favoreciendo la viscosidad del sistema y en consecuencia la formación de las fibras superpuestas para construir mallas estables mediante esta interesante técnica, como se evidencia en la figura 7.

En la siguiente figura, se aprecia que fue posible obtener fibras continuas dispuestas aleatoriamente por capas para el caso de las polimezclas, contrario a lo observado para el $\mathrm{CH}$ puro. En dicha figura se tiene que las fibras de PVA mostraron un diámetro promedio de $203 \pm 63 \mathrm{~nm}$, con la formación de algunas gotas. No obstante, al estudiar la morfología de las fibras de las mezclas, se observa como para la formulación PVA:CH (80:20) desaparecen casi por completo estas gotas, presentando un diámetro promedio de $140 \pm 53 \mathrm{~nm}$, con cierta irregularidad en el diámetro de las mismas. En cuanto a las fibras de los derivados, el diámetro promedio de las fibras fue de $145 \pm 73 \mathrm{~nm}$ para la mezcla PVA:CH-Tyr y $142 \pm 46 \mathrm{~nm}$ para PVA:CH-Leu, pero reaparece la formación de gotas e irregularidad en su diámetro. La figura 7 viene acompañada de los respectivos histogramas con la distribución de diámetro de fibras.

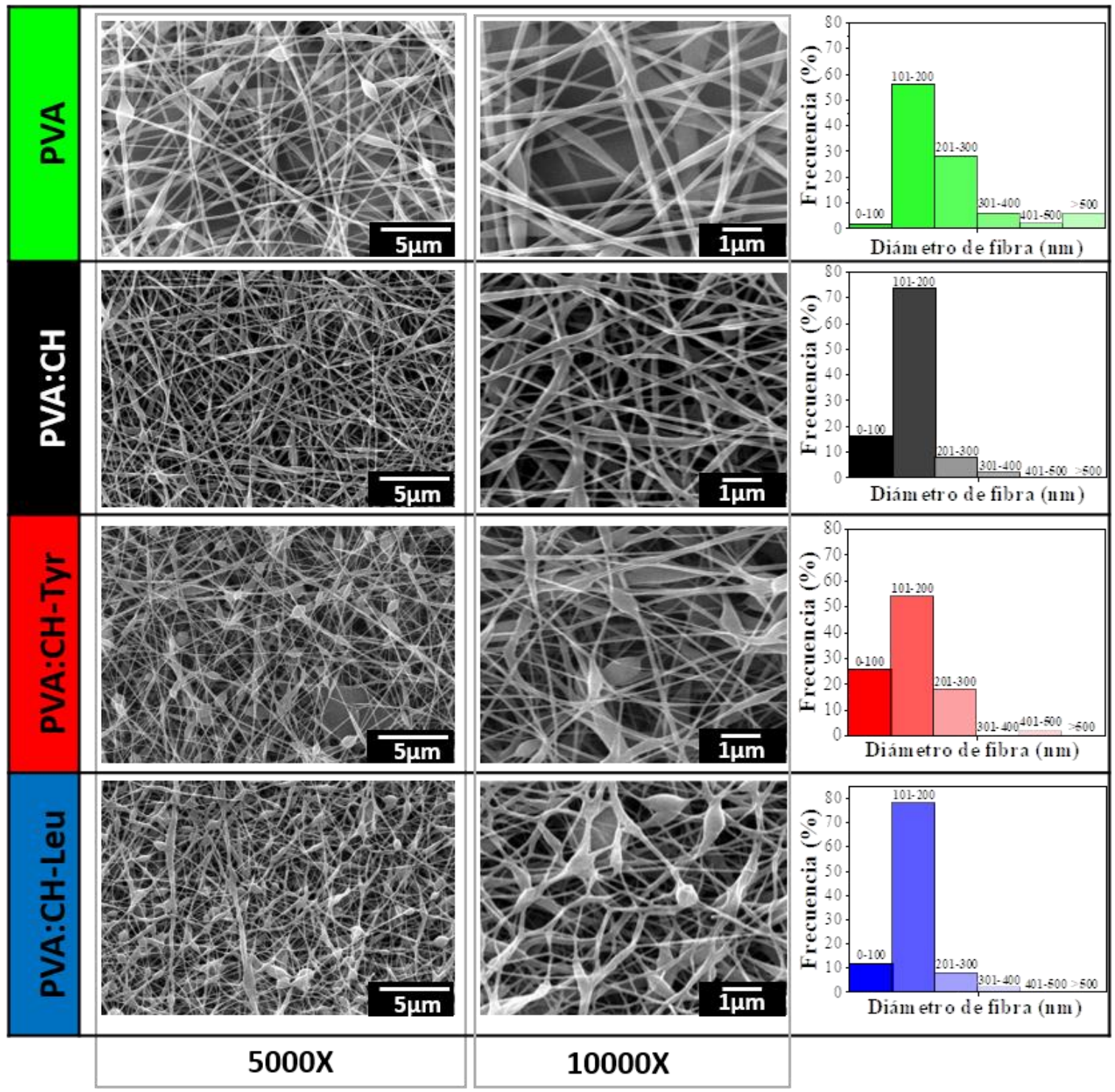

Figura 7: Micrografías SEM (5000 y 10000 X) y gráficos de distribución de diámetro de las fibras de PVA, PVA:CH, PVA:CH-Tyr y PVA:CH-Leu. 
En general se puede apreciar que al mezclar PVA con quitosano o los derivados en proporción (80:20) se logran obtener fibras lisas y continuas dispuestas aleatoriamente formando poros interconectados, para dar lugar a los denominados andamios, los cuales permiten biomimetizar una matriz extracelular [58] [60], con potencialidad de uso en la ingeniería de tejidos, o también como sistemas para la liberación de fármacos.

\subsection{Hemocompatibilidad}

El quitosano es un polisacárido catiónico que podría interactuar de forma no específica con la membrana cargada negativamente de los eritrocitos, pudiendo ocasionar lisis celular seguida de la liberación de hemoglobina. Comprometiendo de esta manera la biocompatibilidad del material preparado en base a este biopolímero [43]. Es por ello que se procedió al estudio de la liberación de hemoglobina de eritrocitos humanos mediante técnicas espectrofotométricas, para estimar el porcentaje de hemólisis generado por el CH, CH-Tyr y CH-Leu a diferentes concentraciones, así como de las membranas producto de la mezcla con PVA. En la figura 8 se observan los porcentajes de hemólisis obtenidos.
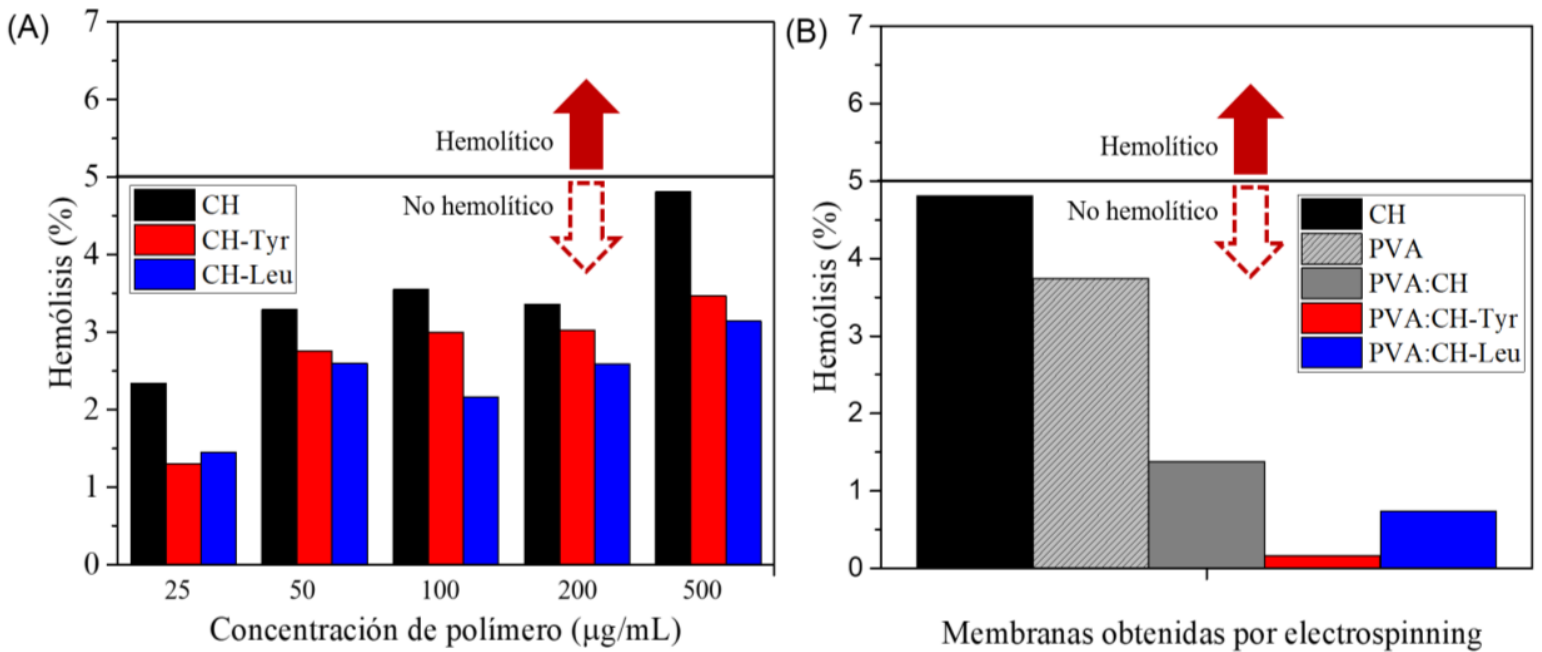

Membranas obtenidas por electrospinning

Figura 8: Porcentaje de hemólisis en eritrocitos humanos de: (A) $\mathrm{CH}, \mathrm{CH}-\mathrm{Tyr}$ y $\mathrm{CH}-\mathrm{Leu}$ a diferentes concentraciones y (B) membranas de $\mathrm{CH}$, PVA, PVA:CH, PVA:CH-Tyr y PVA:CH-Leu.

Según las normas técnicas internacionales, la ISO 10993-5 (1992) considera biocompatible y por tanto no citotóxico un material cuando el índice de hemólisis es inferior al 5\%. De manera más detallada la American Society for Testing and Materials (ASTM F 756-00, 2000), considera que los biomateriales se pueden clasificar en tres categorías según su índice hemolítico (\% de hemólisis), es decir: porcentajes de hemólisis superiores al $5 \%$ se consideran hemolíticos; mientras que aquellos con índice hemolítico entre 5-2\% se clasifican como levemente hemolíticos y finalmente, cuando el material presenta un porcentaje de hemólisis inferior al $2 \%$, se considera no hemolítico.

En la figura 8 se observa que el mayor porcentaje de hemólisis lo presentó el quitosano puro, y está casi en el límite del porcentaje de hemólisis permisible. Este comportamiento se puede atribuir a posibles restos de ácido acético en la muestra. Sin embargo, este valor disminuye una vez realizada la modificación, debido posiblemente al menor número de grupos aminos libres a los largo de la cadena de quitosano, y que, al ser solubles en solución acuosa, no existe la posibilidad de restos de solvente en la muestra, aunado a la disminución del carácter hidrofóbico producto de la N-acilación [61] [48]. En consecuencia, como se muestra en la figura 8A, tanto el quitosano como los conjugados que fueron sintetizados, pueden ser considerados biomateriales no hemolíticos, en base a las normas técnicas y según su concentración, y se pueden considerar biomateriales seguros para aplicaciones biomédicas.

En cuanto al estudio de polimezclas, se ha reportado en la literatura que la combinación de quitosano con otros polímeros, bien sea naturales o sintéticos, no solo permite obtener nuevos materiales con propiedades mecánicas y estructurales mejoradas, sino que al mismo tiempo mejora su carácter biocompatible y 
biodegradable [62] [63] [64]. Adicionalmente, estudios indican que materiales con cadenas hidrofílicas e hidrofóbicas permiten obtener biomateriales hemocompatibles pues minimizan los valores del componente polar y apolar de la energía libre de la interfaz material-sangre [50]. Es por ello, y como podemos ver en la figura 8B, al mezclar PVA con $\mathrm{CH}, \mathrm{CH}-\mathrm{Tyr}$ o $\mathrm{CH}-\mathrm{Leu}$, se presenta una disminución del índice hemolítico a valores menores a $2 \%$, lo que permite inferir que los nuevos derivados de quitosano y sus polimezclas con PVA, son candidatos para el diseño de biomateriales como membranas y andamios.

Adicionalmente, una vez culminado el ensayo de hemólisis para los materiales de partida y los derivados sintetizados, se procedió al estudio morfológico de los eritrocitos a través de microscopía óptica. Donde fue posible apreciar que tanto el quitosano como sus conjugados a diferentes concentraciones no alteraron la morfología celular, como se aprecia en la figura 9.

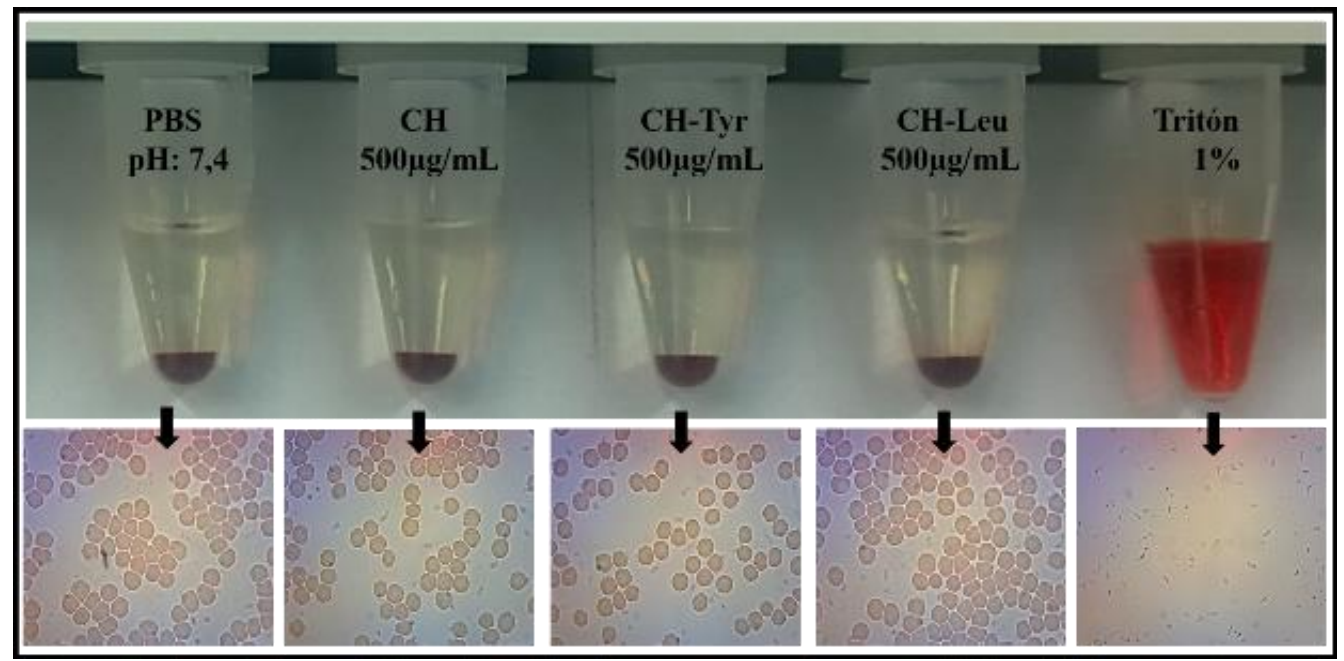

Figura 9: Imagen de la morfología celular de los eritrocitos observado por microscopía óptica 100X (imagen inferior) y en la parte superior se evidencia el aspecto de los tubos eppendorf usados en el ensayo de hemólisis (de la figura 8). Solución PBS como control negativo ( $0 \%$ hemólisis) y el tratamiento con solución de Tritón X-100 al 1\% (v/v) como control positivo (100\% hemólisis).

\section{CONCLUSIONES}

El presente estudio demuestra que fue posible llevar a cabo la síntesis de dos derivados de quitosano a partir de una reacción de $\mathrm{N}$-acilación para injertar covalentemente los aminoácidos L-tirosina y L-leucina a la cadena del polisacárido $\mathrm{CH}$, mediante la formación de un enlace tipo amida entre los grupos amino libres del quitosano y el carbonilo del aminoácido. Esta modificación indujo un cambio en las propiedades físicas y químicas de estos derivados respecto a su precursor. Específicamente, los derivados presentaron una solubilidad mejorada en agua a pH neutro y alteración frente a una degradación hidrolítica, lo cual permite inferir que estos conjugados son prometedores para fabricar estructuras tipo membranas o andamios con potencialidad de uso para aplicaciones biomédicas y/o farmacológicas. Del mismo modo, se pudo mejorar la compatibilidad entre la fase de cada derivado y un polímero sintético como el PVA, preparándose así polimezclas que pudieron generar fibras continuas, a partir de la técnica de electrospinning, y formar estructuras tipo andamio 3D para ingeniería de tejidos. Los resultados de hemocompatibilidad, permiten sustentar la potencialidad de aplicación para este tipo de aplicación.

\section{AGRADECIMIENTOS}

Al grupo de investigación $\mathrm{B}^{5} \mathrm{IDA}$, a la sección de Microscopia Electrónica del Lab-E, también al laboratorio de análisis instrumental de la Universidad Simón Bolívar (Caracas-Venezuela); así como al laboratorio de Desarrollo y Evaluación de Biomateriales-CERTBIO de la Universidad Federal de Campina Grande (Brasil). 


\section{BIBLIOGRAFÍA}

[1] WAHAB, I.F., ABD RAZAK, S.I., "Polysaccharides as Composite Biomaterials", In: Composites from Renewable and Sustainable Materials, IntechOpen, pp. 65-84, 2016.

[2] ALISHAHI, A. "Chitosan: A Bioactive Polysaccharide in Marine-Based Foods", In: The Complex World of Polysaccharides, IntechOpen, pp. 409-428, 2012.

[3] RACHED, R., DA SILVA LIMA, R., VINICIUS, M., "Processo de produção de quitosana utilizando exoesqueletos de camarão espécie Litopenaeus vannamei visualizada por microscopia eletrônica de varredura (MEV)", In: Congresso Técnico Científico da Engenharia e da Agronomia - CONTECC'2016, Iguazú, 2016.

[4] RINAUDO, M., “Chitin and chitosan: Properties and applications”, Progress in Polymer Science, v. 31, n. 7, pp. 603-632, 2006.

[5] DASH, M., CHIELLINI, F., OTTENBRITE, R., et al., "Chitosan-A versatile semi-synthetic polymer in biomedical applications", Progress in Polymer Science, v. 36, n. 8, pp. 981-1014, 2011.

[6] MONTEnEGRO, T., MONTENEGRO, T., MEDEIROS, H., et al., "Microbiological Chitosan: Potential Application as Anticariogenic Agent", In: Practical Applications in Biomedical Engineering, IntechOpen, pp. 229-244, 2013.

[7] HARISH, K., THARANATHAN, R., "Chitin/chitosan: modifications and their unlimited application potential an overview", Trends in Food Science \& Technology, v. 18, n. 3, pp. 117-131, 2007.

[8] FAI CHEUNH, R.C.N.B., WONG, J.H., CHAN, W.Y., "Chitosan: An Update on Potential Biomedical and Pharmaceutical Applications", Mar Drugs, v. 13, n. 8, pp. 5156-5186, 2015.

[9] SZYMA'NSKA, E., WINNICKA, K.., "Stability of Chitosan-A Challenge for Pharmaceutical and Biomedical Applications”, Mar Drugs, v. 13, n. 4, pp. 1819-1846, 2015.

[10] IBRAHIM, H.M., EL-ZAIRY, E., "Chitosan as a Biomaterial-Structure, Properties, and Electrospun Nanofibers", In: Concepts, Compounds and the Alternatives of Antibacterials, IntechOpen, pp. 81-101, 2015.

[11] LI, S., XIONG, Q., LAI, X., et al., "Molecular Modification of Polysaccharides and Resulting Bioactivities", Comprehensive Reviews in Food Science and Food Safety, v. 15, n. 2, pp. 237-250, 2016.

[12] JAYAKUMAR, R., SELVAMURUGAN, N., NAIR, S., et al., "Preparative methods of phosphorylated chitin and chitosan-An overview”, International Journal of Biological Macromolecules, v. 43, n. 3, pp. 221-225, 2008.

[13] MUÑOZ, G., ZULUAGA, H., “Chitosan, Chitosan Derivatives and their Biomedical Applications", In: Biological Activities and Application of Marine Polysaccharides, IntechOpen, pp. 87-106, 2017.

[14] VONGCHAN, P., SAJOMSANG, W., SUBYEN, D., et al., "Anticoagulant activity of a sulfated chitosan”, Carbohydrate Research, v. 337, n. 13, pp. 1239-1242, 2002.

[15] TAMURA, H., JAYAKUMAR, R., NEW, N., et al., "Sulfated chitin and chitosan as novel biomaterials", International Journal of Biological Macromolecules, v. 40, n. 3, pp. 175-181, 2007.

[16] ROLDO, M., HORNOF, M., CALICETI, P., et al., "Mucoadhesive thiolated chitosans as platforms for oral controlled drug delivery: synthesis and in vitro evaluation", European Journal of Pharmaceutics and Biopharmaceutics, v. 57, n. 1, pp. 115-121, 2004.

[17] YIN, L., DING, J., HE, C., et al., "Drug permeability and mucoadhesion properties of thiolated trimethyl chitosan nanoparticles in oral insulin delivery”, Biomaterials, v. 30, n. 29, pp. 5691-5700, 2009.

[18] TAN, H., MA, R., LIN, C., et al., "Quaternized Chitosan as an Antimicrobial Agent: Antimicrobial Activity, Mechanism of Action and Biomedical Applications in Orthopedics", International Journal of Molecular Sciences, v. 14, n. 1, pp. 1854-1869, 2013.

[19] SAJOMSANG, W., TANTAYANON, S., TANGPASUTHADOL, V., et al., "Quaternization of N-aryl chitosan derivatives: synthesis, characterization, and antibacterial activity", Carbohydrate Research, v. 344, n. 18, pp. 2502-1511, 2009.

[20] DE OLIVEIRA, P., TAKAKI, M., GORAYEB, T., et al., "Synthesis, characterization and antifungal activity of quaternary derivatives of chitosan on Aspergillus flavus", Microbiological Research, v. 168, n. 1, pp. 50-55, 2013. 
[21] PHILIPPOVA, O., KORCHAGINA, E., "Chitosan and Its Hydrophobic Derivatives: Preparation and Aggregation in Dilute Aqueous Solutions", Polymer Science Series A, v. 54, n. 7, pp. 552-572, 2012.

[22] MA, G., YANG, D., TAN, H., et al., "Preparation and Characterization of N-alkylated Chitosan Derivatives", Journal of Applied Polymer Science, v. 109, n. 2, pp. 1093-1098, 2008.

[23] TIEN, C., LACROIX, M., SZABO, P., et al., "N-acylated chitosan: hydrophobic matrices for controlled drug release", Journal of Controlled Release, v. 93, n. 1, pp. 1-13, 2003.

[24] JAYAKUMARA, R., PRABAHARANA, M., REISA, R., et al., "Graft copolymerized chitosan—present status and applications", Carbohydrate Polymers, v. 62, n. 2, pp. 142-158, 2005.

[25] ALVES, N., MANOA, J., "Chitosan derivatives obtained by chemical modifications for biomedical and environmental applications", International Journal of Biological Macromolecules, v. 43, n. 5, pp. 401-414, 2008.

[26] MOURYA, V., INAMDAR, N., "Chitosan-modifications and applications: Opportunities galore", Reactive \& Functional Polymers, v. 68, n. 6, pp. 1013-1051, 2008.

[27] CARRERO, M., POSADA, J., SABINO, M., "Intelligent copolymers based on poly (Nisopropylacrylamide) PNIPAm with potential use in biomedical applications. Part i: PNIPAm functionalization with 3-butenoic acid and piperazina", International Journal Of Advances In Medical Biotechnology, v. 1, n. 1, pp. 23-31, 2018.

[28] DE ARAÚJO, E., CAVALCANTE, S., ALVES, D., et al., "Modified chitosan-based bioactive material for antimicrobial application: Synthesis and characterization", International Journal of Biological Macromolecules, v. 117, pp. 640-647, 2018.

[29] DEMETGÜL, C., BEYAZIT, N., "Synthesis, characterization and antioxidant activity of chitosan-chromone derivatives", Carbohydrate Polymers, v. 181, pp. 812-817, 2018.

[30] CASETTARI, L., VLLASALIU, D., LAM, J., et al., "Biomedical applications of amino acid-modified chitosans: A review", Biomaterials, v. 33, n. 30, pp. 7565-7583, 2012.

[31] ALIPOUR, S., NOURI, M., MOKHTARI, J., et al., "Electrospinning of poly(vinyl alcohol)-water-soluble quaternized chitosan derivative blend", Carbohydrate Research, v. 344, n. 18, pp. 2496-2501, 2009.

[32] PRASAD, T., SHABEENA, E., VINOD, D., et al., "Characterization and in vitro evaluation of electrospun chitosan/polycaprolactone blend fibrous mat for skin tissue engineering", Journal of Materials Science: Materials in Medicine, v. 26, n. 28, 2015.

[33] OHKAWA, K., CHA, D., KIM, H., et al., "Electrospinning of Chitosan", Macromolecular Rapid Communications, v. 25, n. 18, pp. 1600-1605, 2004.

[34] BHATTARAI, N., EDMONDSON, D., VEISEH, O., et al., "Electrospun chitosan-based nanofibers and their cellular compatibility”, Biomaterials, v. 26, n. 31, pp. 6176-6184, 2005.

[35]THOTAKURA, N., DADARWAL, M., KUMAR, P., et al., "Chitosan-Stearic Acid Based Polymeric Micelles for the Effective Delivery of Tamoxifen: Cytotoxic and Pharmacokinetic Evaluation", American Association of Pharmaceutical Scientists, v. 18, n. 3, pp. 759-768, 2017.

[36] THOTAKURA, N., DADARWAL, M., KUMAR, R., et al., "Chitosan-Palmitic Acid Based Polymeric Micelles as Promising Carrier for Circumventing Pharmacokinetic and Drug Delivery Concerns of Tamoxifen", International Journal of Biological Macromolecules, v. 102, pp. 1220-1225, 2017.

[37] LASKAR, K., MOHD FAISAL, S., et al., "Undec-10-enoic acid functionalized chitosan based novel nanoconjugate: an enhanced anti-bacterial/biofilm and anti-cancer potential", Carbohydrate Polymers, v. 166, pp. 1423, 2017.

[38] TAMER, T., VALACHOVÁ, K., HASSANC, M., et al., "Chitosan/hyaluronan/edaravone membranes for anti-inflammatory wound dressing: In vitro and in vivo evaluation studies", Materials Science \& Engineering C, v. 90, pp. 227-235, 2018.

[39] SOWJANYA, J., SINGH, J., MOHITA, T., et al., "Biocomposite scaffolds containing chitosan/alginate/nano-silica for bone tissue engineering", Colloids and Surfaces B: Biointerfaces, v. 109, pp. 294-300, 2013. 
[40] TRONCI, G., BUIGA, P., ALHILOU, A., et al., "Hydrolytic and lysozymic degradability of chitosan systems with heparin-mimicking pendant groups", Materials Letters, v. 188, pp. 359-363, 2017.

[41] EVANS, B., NELSON, C., YU, S., et al., "Ex Vivo Red Blood Cell Hemolysis Assay for the Evaluation of pH-responsive Endosomolytic Agents for Cytosolic Delivery of Biomacromolecular Drugs", Journal of Visualized Experiments, v. 73, pp. 1-5, 2013.

[42] SARWAR, A., KATAS, H., SAMSUDIN, S., et al., "Regioselective Sequential Modification of Chitosan via Azide-Alkyne Click Reaction: Synthesis, Characterization, and Antimicrobial Activity of Chitosan Derivatives and Nanoparticles", Journal PLOS ONE, pp. 1-22, 2015.

[43] SHARMA, D., SINGH, J., "Synthesis and Characterization of Fatty Acid Grafted Chitosan Polymerand their Nanomicelles for Non-Viral Gene Delivery Applications", Bioconjugate chemistry, v. 28, n. 11, pp. 2772-2783, 2017.

[44] BRUGNEROTTO, J., LIZARDI, J., GOYCOOLEA, F., et al., "An infrared investigation in relation with chitin and chitosan characterization", Polymer, v. 42, n. 8, pp. 3569-3580, 2001.

[45] XIAO, B., WAN, Y., ZHAO, M., et al., "Preparation and characterization of antimicrobial chitosan-Narginine with different degrees of substitution”, Carbohydrate Polymers, v. 83, n. 1, pp. 144-150, 2011.

[46] XIANG, Y., SI, J., ZHANG, Q., et al., "Homogeneous graft copolymerization and characterization of novel artificial glycoprotein: Chitosan-poly(L-tryptophan) copolymers with secondary structural side chains", Journal of Polymer Science: Part A: Polymer Chemistry, v. 47, n. 3, pp. 925-934, 2009.

[47] MUHSIN, M., GEORGE, G., BEAGLEY, K., FERRO, V., ARMITAGE, C., et al., "Synthesis and Toxicological Evaluation of a Chitosan L Leucine Conjugate for Pulmonary Drug Delivery Applications", Biomacromolecules, v. 15, n. 10, pp. 3596-3607, 2014.

[48] BALAN, V., VERESTIUC, L., "Strategies to improve chitosan hemocompatibility: A review", European Polymer Journal, v. 53, pp. 171-188, 2014.

[49]BISEN, D., BHATT, R., BAJPAI, A., et al., "Reverse indentation size effects in gamma irradiated blood compatible blend films of chitosan-poly (vinyl alcohol) for possible medical applications" Materials Science and Engineering C, v. 71, pp. 982-993, 2017.

[50] SEVASTIANOV, V., DRUSHLYAK, I., EBERHART, R., et al., "Blood compatible biomaterials: Hydrophilicity vs. hydrophobicity", Macromolecular Symposia, v. 103, n. 1, pp. 1-4, 1996.

[51] THEVENOT, P., HU, W., TANG, L., "Surface chemistry influence implant biocompatibility", Current Topics in Medicinal Chemistry, v. 8, n. 4, pp. 270-280, 2008.

[52] CLASEN, C., WILHELMS, T., KULICKE, W., "Formation and Characterization of Chitosan Membranes", Biomacromolecules, v. 7, n. 11, pp. 3210-3222, 2006.

[53] CROISIER, F., JÉRÔME, C., "Chitosan-based biomaterials for tissue engineering", European Polymer Journal, v. 49, n. 4, pp. 780-792, 2013

[54] NEAU, S., ZHANG, H., "In vitro degradation of chitosan by a commercial enzyme preparation: e!ect of molecular weight and degree of deacetylation", Biomaterials, v. 22, n. 12, pp. 1653-1658, 2001.

[55] MA, X., WANG, W., YI, H., REN, D., "The enzymatic degradation and swelling properties of chitosan matrices with different degrees of N-acetylation", Carbohydrate Research, v. 340, n. 15, pp. 2403-2410, 2005.

[56] DHANDAYUTHAPANI, B., YOSHIDA, Y., MAEKAWA, T., et al., "Polymeric Scaffolds in Tissue Engineering Application: A Review”, International Journal of Polymer Science, v. 2011, pp. 1-19, 2011.

[57] HAYASHI, T., "Biodegradable polymers for biomedical uses" Progress in Polymer Science, v. 19, n. 4, pp. 663-702, 1994.

[58] JU, W., COOPER, J., "Fibrous Scaffolds for Tissue Engineering", In: Biomaterials for Tissue Engineering Applications, Springer, 2011.

[59] GAMBOA, W., MANTILLA, O., CASTILLO, V., "Producción de micro y nanofribas a partir de la técnica "electrospinning" para aplicaciones farmacológicas", En: VII Congreso de la Sociedad Cubana de Bioingeniería, La Habana, 2007. 
[60] Li, Y., BOU-AKL, T., "Electrospinning in Tissue Engineering”, In: Electrospinning - Material, Techniques, and Biomedical Applications, IntechOpen, pp. 117-139, 2016.

[61] SINCH, D., RAY, A., "Graft Copolymerization of 2-Hydroxyethylmethacrylate onto Chitosan Films and Their Blood Compatibility”, Journal of Applied Polymer Science, v. 53, n. 8, pp. 1115-1121, 1994.

[62] WU, Y., YU, S., MI, F., et al., "Preparation and characterization on mechanical and antibacterial properties of chitsoan/cellulose blends", Carbohydrate Polymers, v. 57, n. 4, pp. 435-440, 2004.

[63] MAHONEY, C., MCCULlOUGH, M., SANKAR, J., et al., "Nanofibrous structure of chitosan for biomedical applications”, Journal Nanomedicine \& Biotherapeutic Discovery, v. 2, n.1, pp. 1-9, 2012.

[64] SALAS, C., THOMPSON, Z., BHATTARAI, N., “Electrospun chitosan fibers”, In: Electrospun nanofibers, Elsevier, 2017.

\section{ORCID}

María Gabriela Carrero Gallardo

Rossemberg Cardoso Barbosa

Marcus Vinicius Lia fook

Marcos Antonio Sabino https://orcid.org/0000-0002-3805-5387

https://orcid.org/0000-0002-8551-5251

https://orcid.org/0000-0002-8566-920X

https://orcid.org/0000-0001-8316-7241 